\title{
Effect of Ularitide on Cardiovascular Mortality in Acute Heart Failure
}

\author{
M. Packer, C. O'Connor, J.J.V. McMurray, J. Wittes, W.T. Abraham, S.D. Anker, \\ K. Dickstein, G. Filippatos, R. Holcomb, H. Krum,* A.P. Maggioni, A. Mebazaa, \\ W.F. Peacock, M.C. Petrie, P. Ponikowski, F. Ruschitzka, D.J. van Veldhuisen, \\ L.S. Kowarski, M. Schactman, and J. Holzmeister, \\ for the TRUE-AHF Investigators'
}

The authors' full names, academic degrees, and affiliations are listed in the Appendix. Address reprint requests to Dr. Packer at the Baylor Heart and Vascular Institute, Baylor University Medical Center, 621 N. Hall St., Dallas, TX 75226, or at milton.packer@baylorhealth.edu.

*Deceased.

$\uparrow$ A complete list of the investigators in the Trial of Ularitide Efficacy and Safety in Acute Heart Failure (TRUE-AHF) is provided in the Supplementary Appendix, available at NEJM.org.

This article was published on April 12, 2017, at NEJM.org.

N Engl J Med 2017;376:1956-64. DOI: $10.1056 /$ NEJMoal601895

Copyright (๑ 2017 Massachusetts Medical Society.
A BSTRACT

\section{BACKGROUND}

In patients with acute heart failure, early intervention with an intravenous vasodilator has been proposed as a therapeutic goal to reduce cardiac-wall stress and, potentially, myocardial injury, thereby favorably affecting patients' long-term prognosis.

\section{METHODS}

In this double-blind trial, we randomly assigned 2157 patients with acute heart failure to receive a continuous intravenous infusion of either ularitide at a dose of 15 ng per kilogram of body weight per minute or matching placebo for 48 hours, in addition to accepted therapy. Treatment was initiated a median of 6 hours after the initial clinical evaluation. The coprimary outcomes were death from cardiovascular causes during a median follow-up of 15 months and a hierarchical composite end point that evaluated the initial 48-hour clinical course.

\section{RESULTS}

Death from cardiovascular causes occurred in 236 patients in the ularitide group and 225 patients in the placebo group (21.7\% vs. $21.0 \%$; hazard ratio, 1.03 ; $96 \%$ confidence interval, 0.85 to $1.25 ; \mathrm{P}=0.75$ ). In the intention-to-treat analysis, there was no significant between-group difference with respect to the hierarchical composite outcome. The ularitide group had greater reductions in systolic blood pressure and in levels of $\mathrm{N}$-terminal pro-brain natriuretic peptide than the placebo group. However, changes in cardiac troponin $\mathrm{T}$ levels during the infusion did not differ between the two groups in the $55 \%$ of patients with paired data.

\section{CONCLUSIONS}

In patients with acute heart failure, ularitide exerted favorable physiological effects (without affecting cardiac troponin levels), but short-term treatment did not affect a clinical composite end point or reduce long-term cardiovascular mortality. (Funded by Cardiorentis; TRUE-AHF ClinicalTrials.gov number, NCT01661634.) 
CUTE PRESENTATION WITH NEW-ONSET heart failure and rapid worsening of preexisting heart failure are two of the most common causes of hospitalization worldwide. ${ }^{1}$ The disorder in each case is characterized by intravascular volume expansion and ventricular distention, which may cause myocardial injury in the absence of coronary artery disease or occlusion. ${ }^{2-4}$ Episodes are associated with an accelerated rate of disease progression; each hospitalization for heart failure increases the risk of subsequent admissions as well as the risk of death from cardiovascular causes. ${ }^{5}$

The first few hours after the initial presentation with acute heart failure may represent a period of substantial myocardial vulnerability, which is characterized by rapid increases in cardiacwall stress. ${ }^{6}$ Patients with acute heart failure have elevated levels of $\mathrm{N}$-terminal pro-brain natriuretic peptide (NT-proBNP) and cardiac troponin,,$^{2-4,6}$ thus mimicking features of an acute coronary syndrome. ${ }^{7}$ These observations have led to the hypothesis that very early short-term interventions that attenuate cardiac-wall stress may reduce myocardial injury during a critical period and have favorable long-term effects (Fig. S1 in the Supplementary Appendix, available with the full text of this article at NEJM.org). ${ }^{8-12}$ Early vasodilator treatment has been proposed as a therapeutic goal in recent guidelines. ${ }^{13}$ Shortterm interventions have been associated with both favorable and unfavorable longer-term effects on morbidity and mortality. ${ }^{14-16}$

In the Trial of Ularitide Efficacy and Safety in Acute Heart Failure (TRUE-AHF), we examined whether the prompt administration of the natriuretic peptide ularitide in doses sufficient to reduce myocardial-wall stress would reduce the long-term risk of cardiovascular death in patients with acute heart failure. ${ }^{17}$ Ularitide, a chemically synthesized analogue of the naturally occurring vasodilator urodilatin, was selected as the study drug because it had been associated with hemodynamic and clinical benefits in two previous randomized clinical trials. ${ }^{18,19}$

\section{METHODS}

\section{TRIAL DESIGN AND OVERSIGHT}

TRUE-AHF was a randomized, double-blind, parallel-group, placebo-controlled, event-driven trial. ${ }^{17}$ The trial protocol and the statistical analysis plan are available at NEJM.org. The ethics committee at each trial center approved the trial, and all the patients provided written informed consent.

The executive committee, together with the sponsor (Cardiorentis), developed and amended the protocol and oversaw the recruitment of patients and the analysis of data; the committee provided an independent interpretation of the results. ${ }^{17}$ A clinical-events committee classified deaths and adjudicated nonfatal events, and a medical review committee examined case summaries for unidentified instances of in-hospital heart-failure events in a blinded manner. An independent data and safety monitoring committee reviewed the safety of the patients and the results of interim analyses. Data were analyzed according to a predefined statistical analysis plan, and an independent statistician verified and replicated the analyses. The first author, who had unrestricted access to the data, prepared the drafts of the manuscript, which were then reviewed and edited by all the authors, independent of the sponsor. The authors assume responsibility for the accuracy and completeness of the analyses; the last author attests to the fidelity of the trial to the protocol.

\section{PATIENTS}

Men and women between the ages of 18 and 85 years were eligible to enroll in the trial if they met all the following criteria: an unplanned emergency department visit or hospitalization for acute heart failure, dyspnea at rest that had worsened during the previous week, evidence of heart failure on chest radiography, a blood BNP level of more than 500 pg per milliliter or an NT-proBNP level of more than 2000 pg per milliliter, and the possibility of initiating the study drug within 12 hours after the initial clinical evaluation. Patients who continued to have dyspnea at rest for at least 2 hours after the intravenous administration of at least $40 \mathrm{mg}$ of furosemide (or the equivalent) and who had a systolic blood pressure between $116 \mathrm{~mm} \mathrm{Hg}$ and $180 \mathrm{~mm} \mathrm{Hg}$ were eligible for randomization. (A full list of the exclusion criteria is provided in the Supplementary Appendix.)

\section{PROCEDURES}

Patients underwent randomization in a 1:1 ratio in a double-blind manner to receive a continuous intravenous infusion of either ularitide at a dose of $15 \mathrm{ng}$ per kilogram of body weight per minute 


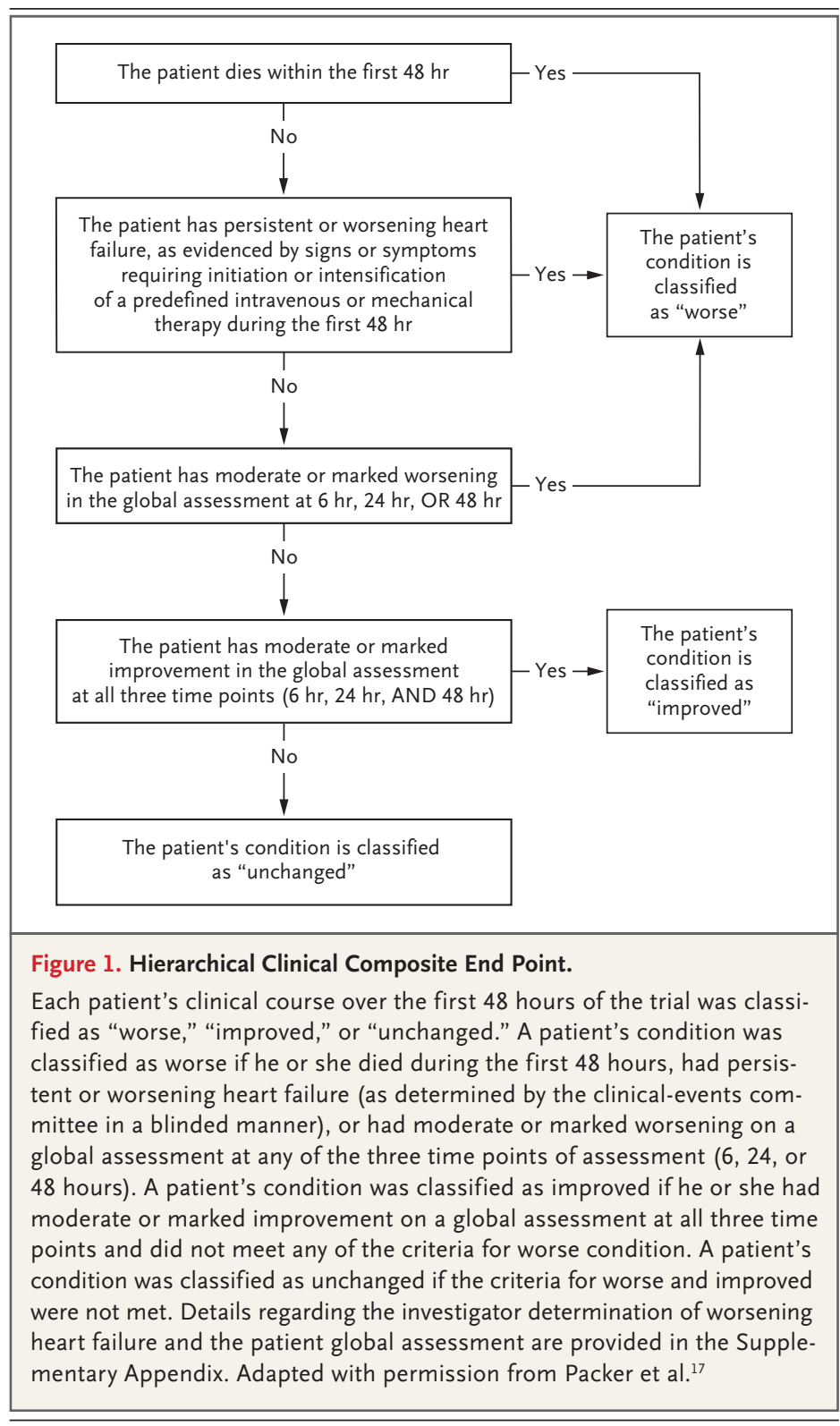

or matching placebo for 48 hours. This dose had produced meaningful decreases in cardiac filling pressures in previous trials. ${ }^{18,19}$ The rate of infusion of the study drug was reduced or discontinued if symptomatic hypotension developed or if there was a decrease in the systolic blood pressure to a value of less than $100 \mathrm{~mm} \mathrm{Hg}$ or a decrease of more than $40 \mathrm{~mm} \mathrm{Hg}$ from baseline.

Investigators used a patient global assessment to inquire about changes in symptoms of heart failure at 6, 24, and 48 hours after the initiation of the study infusion (see the Supplementary Appendix). Levels of NT-proBNP and high-sensitivity troponin $\mathrm{T}$ were assessed before the start of the infusion and after 48 hours. At 48 hours, the study-drug infusion was stopped.

For the first 120 hours, patients were monitored for persistent or worsening heart failure. The investigators described the features of these in-hospital heart-failure events and the interventions that were used to treat them. (The definitions that were used to identify and adjudicate these episodes are provided in the Supplementary Appendix. ${ }^{15,17}$ ) In addition, patients were allowed to receive any oral or intravenous medications for heart failure that were deemed to be clinically appropriate. Patients were followed for the occurrence of rehospitalization for 6 months and for the occurrence of death for the entire duration of the trial.

\section{PRIMARY AND SECONDARY OUTCOMES}

The trial had two primary outcomes: cardiovascular death over the entire duration of the trial and the clinical course of patients during the first 48 hours, as assessed by a hierarchical clinical composite end point (Fig. 1, with additional details provided in the Supplementary Appendix). ${ }^{15,20}$ When the trial was initiated, it focused only on the short-term clinical course of patients, and the clinical composite was the sole primary end point. ${ }^{17}$ However, after the Relaxin for the Treatment of Acute Heart Failure (RELAX-AHF) trial reported a potential mortality reduction, ${ }^{14}$ we added cardiovascular mortality as a coprimary end point after approximately 40 patients had been enrolled and then redesigned the trial to extend follow-up to achieve a predetermined number of events. We divided the alpha level across the two primary end points, with 0.04 assigned to cardiovascular mortality and 0.01 to the hierarchical clinical composite end point.

The secondary end points of the trial are summarized in the Supplementary Appendix. These end points, which were to be tested hierarchically, included the length of stay in the hospital and in the intensive care unit during the index episode, the number of episodes of in-hospital heart-failure events through the first 120 hours, the proportion of patients with an in-hospital heart-failure event through the first 120 hours, rehospitalization for heart failure within 30 days after the initial hospital discharge, the time until completion of intravenous treatment for heart failure, and death or rehospitalization for a cardiovascular cause during the first 180 days. 


\section{STATISTICAL ANALYSIS}

The sample size was based on the primary efficacy analysis of cardiovascular mortality, which was tested at a two-sided significance level of 0.04 . We expected to recruit 2152 patients over a 2-year period with a follow-up of at least 1 year to observe 652 deaths from cardiovascular causes, a trial design that provided a power of $90 \%$ to detect a relative reduction of $22 \%$ in the risk of cardiovascular death. These assumptions were based on a 6-month rate of cardiovascular death of $8.6 \%$ in the ularitide group and $11.0 \%$ in the placebo group. We evaluated time-to-event data with Kaplan-Meier estimates and used Cox proportional-hazards models to calculate hazard ratios, 96\% confidence intervals, and two-sided $\mathrm{P}$ values for the risk of cardiovascular death, using age, sex, baseline systolic blood pressure ( $<140 \mathrm{~mm} \mathrm{Hg}$ vs. $\geq 140 \mathrm{~mm} \mathrm{Hg}$ ), time from the first clinical evaluation until the initiation of the study-drug infusion ( $\leq 6$ hours vs. $>6$ hours), and region as prespecified covariates.

We performed the primary efficacy analysis for the hierarchical clinical composite end point at a two-sided significance level of 0.01 . We used the Cochran-Mantel-Haenszel test to compare the differences in the distribution of ranks, with the time from the first physician evaluation until the initiation of the study-drug infusion and baseline systolic blood pressure as stratification variables. All P values that were calculated for analyses other than the primary end points are nominal (see the Supplementary Appendix).

We included data from all the patients who had undergone randomization in the analyses of the primary and secondary outcomes, according to the intention-to-treat principle, and used multiple imputation to account for missing data. The trial design incorporated an option to increase the total enrollment on the basis of the results of a midpoint interim analysis; this option was not exercised. A second interim analysis that was performed for futility after all the enrolled patients had been followed for at least 6 months led to termination of the trial because no benefit was seen with respect to cardiovascular mortality.

\section{RESULTS}

\section{PATIENTS}

From August 2012 through May 2014, we enrolled 2157 patients at 156 centers in 23 countries. A total of 1088 patients were assigned to receive ularitide and 1069 to receive placebo (Fig. S2 in the Supplementary Appendix). The characteristics of the two groups were similar at baseline (Table 1, and Table S1 in the Supplementary Appendix).

\section{STUDY-DRUG ADMINISTRATION AND FOLLOW-UP}

We administered the study drug to 1072 patients in the ularitide group and 1056 in the placebo group at a median of 6.1 hours (interquartile range, 4.6 to 8.4 ) after the initial clinical evaluation. (Reasons for nontreatment are provided in Fig. S2 in the Supplementary Appendix.) Ularitide was discontinued in 194 patients (18.1\%) and placebo in 78 patients $(7.4 \%)$; the dose was reduced (but not discontinued) in 106 patients (9.9\%) in the ularitide group and in $55(5.2 \%)$ in the placebo group $(\mathrm{P}<0.001$ for both comparisons) (Table S2 in the Supplementary Appendix). The primary reason for both discontinuation and dose reduction was hypotension. One patient in the placebo group was lost to follow-up for cardiovascular mortality. The median duration of follow-up was 15 months, with no significant difference between the groups; follow-up ended in January 2016.

\section{PRIMARY AND SECONDARY OUTCOMES}

The coprimary outcome of death from cardiovascular causes occurred in 236 patients in the ularitide group and 225 patients in the placebo group (21.7\% vs. $21.0 \%$; hazard ratio, $1.03 ; 96 \%$ confidence interval [CI], 0.85 to $1.25 ; \mathrm{P}=0.75$ ) (Table 2 and Fig. 2). The lack of a significant difference between the two groups was seen consistently across prespecified subgroups (except for a nominally significant interaction for geographical region), as well as in subgroups that were defined according to baseline levels of NT-proBNP and cardiac troponin (Fig. S3 in the Supplementary Appendix). The distribution of responses for the clinical composite (the second coprimary outcome) did not differ significantly between the groups (Table 2, and Table S3 in the Supplementary Appendix). In a post hoc analysis that excluded the patients who had been identified before the database lock as having been ineligible for the trial, a benefit of ularitide was shown with respect to the hierarchical clinical composite outcome $(\mathrm{P}=0.03)$ but not with respect to cardiovascular mortality (Table S4 in the Supplementary Appendix). 
Table 1. Demographic and Clinical Characteristics of the Patients at Baseline.*

\begin{tabular}{|c|c|c|}
\hline Characteristic & $\begin{array}{l}\text { Ularitide } \\
(\mathrm{N}=1088)\end{array}$ & $\begin{array}{l}\text { Placebo } \\
(\mathrm{N}=1069)\end{array}$ \\
\hline Age $-y r$ & $68.7 \pm 11.4$ & $68.3 \pm 11.3$ \\
\hline \multicolumn{3}{|l|}{ Group - no. (\%) } \\
\hline$<65 \mathrm{yr}$ & $362(33.3)$ & $387(36.2)$ \\
\hline$\geq 65 \mathrm{yr}$ & $726(66.7)$ & $682(63.8)$ \\
\hline Male sex — no. (\%) & $714(65.6)$ & $706(66.0)$ \\
\hline Nonblack race - no. $(\%) \dagger$ & $989(90.9)$ & $973(91.0)$ \\
\hline Body-mass indext & $29.3 \pm 6.3$ & $29.2 \pm 6.7$ \\
\hline \multicolumn{3}{|l|}{ Left ventricular ejection fraction — no./total no. (\%) } \\
\hline$<40 \%$ & $445 / 690(64.5)$ & $449 / 681(65.9)$ \\
\hline$\geq 40 \%$ & $245 / 690(35.5)$ & $232 / 681(34.1)$ \\
\hline \multicolumn{3}{|l|}{ Region - no. (\%) } \\
\hline North America & $159(14.6)$ & $152(14.2)$ \\
\hline Latin America & $171(15.7)$ & $160(15.0)$ \\
\hline Western Europe & $212(19.5)$ & $208(19.5)$ \\
\hline Eastern Europe & $546(50.2)$ & $549(51.4)$ \\
\hline \multicolumn{3}{|c|}{$\begin{array}{l}\text { Interval between clinical evaluation and initiation of treatment } \\
\qquad- \text { no. (\%) }\end{array}$} \\
\hline$\leq 6 \mathrm{hr}$ & $533(49.0)$ & $528(49.4)$ \\
\hline$>6 \mathrm{hr}$ & $555(51.0)$ & $541(50.6)$ \\
\hline \multicolumn{3}{|l|}{ Clinical history — no. (\%) } \\
\hline Coronary artery disease & $556(51.1)$ & $549(51.4)$ \\
\hline Diabetes & $414(38.1)$ & $429(40.1)$ \\
\hline Previous episode of heart failure & $825(75.8)$ & $806(75.4)$ \\
\hline \multicolumn{3}{|l|}{ NYHA class within past month - no./total no. (\%) } \\
\hline 1 & $40 / 816(4.9)$ & $46 / 830(5.5)$ \\
\hline II & $265 / 816(32.5)$ & $269 / 830(32.4)$ \\
\hline III & $396 / 816(48.5)$ & $398 / 830(48.0)$ \\
\hline IV & $115 / 816(14.1)$ & $117 / 830(14.1)$ \\
\hline \multicolumn{3}{|l|}{ Blood pressure $-\mathrm{mm} \mathrm{Hg}$} \\
\hline Systolic & $134.2 \pm 17.8$ & $135.1 \pm 17.9$ \\
\hline Diastolic & $79.0 \pm 13.1$ & $79.4 \pm 13.5$ \\
\hline Heart rate - beats/min & $85.4 \pm 18.8$ & $85.6 \pm 19.1$ \\
\hline \multicolumn{3}{|l|}{ Laboratory values } \\
\hline Median N-terminal proBNP (IQR) $-\mathrm{pg} / \mathrm{ml}$ & $\begin{array}{c}7156 \\
(4230-13,238)\end{array}$ & $\begin{array}{c}7121 \\
(3974-12,599)\end{array}$ \\
\hline Median cardiac troponin T (IQR) - pg/ml & $34(22-54)$ & $33(21-54)$ \\
\hline Hemoglobin - g/dl & $13.1 \pm 1.78$ & $13.2 \pm 1.89$ \\
\hline Serum creatinine $-\mathrm{mg} / \mathrm{dl}$ & $1.24 \pm 0.37$ & $1.23 \pm 0.35$ \\
\hline \multicolumn{3}{|l|}{ Treatment at randomization — no. (\%) } \\
\hline Intravenous nitrates & $101(9.3)$ & $110(10.3)$ \\
\hline Intravenous dobutamine & $4(0.4)$ & $6(0.6)$ \\
\hline
\end{tabular}

* Plus-minus values are means \pm SD. There were no significant differences between the groups. The number of patients with available data is provided in Table S1 in the Supplementary Appendix. To convert the values for creatinine to micromoles per liter, multiply by 88.4. BNP denotes brain natriuretic peptide, IQR interquartile range, and NYHA New York Heart Association.

$\uparrow$ Race was reported by the patients.

$¥$ The body-mass index is the weight in kilograms divided by the square of the height in meters. 


\begin{tabular}{|c|c|c|c|}
\hline Measure & $\begin{array}{l}\text { Ularitide } \\
(\mathrm{N}=1088)\end{array}$ & $\begin{array}{l}\text { Placebo } \\
(\mathrm{N}=1069)\end{array}$ & P Value \\
\hline \multicolumn{4}{|l|}{ Primary outcomes } \\
\hline Cardiovascular death & $236(21.7)$ & $225(21.0)$ & 0.75 \\
\hline $\begin{array}{l}\text { Hierarchical clinical composite outcome } \leq 48 \mathrm{hr} \text { after randomization } \\
\qquad \text { - no./total no. (\%) }\end{array}$ & & & 0.82 \\
\hline Improved & $508 / 1045(48.6)$ & $490 / 1032(47.5)$ & \\
\hline Unchanged & $468 / 1045(44.8)$ & $456 / 1032(44.2)$ & \\
\hline Worse & $69 / 1045(6.6)$ & $86 / 1032(8.3)$ & \\
\hline \multicolumn{4}{|l|}{ Secondary outcomes* } \\
\hline Median length of hospital stay during first 30 days (IQR) $-\mathrm{hr}$ & $\begin{array}{c}160.8 \\
(96.0 \text { to } 228.9)\end{array}$ & $\begin{array}{c}148.2 \\
(94.0 \text { to } 216.8)\end{array}$ & 0.16 \\
\hline $\begin{array}{l}\text { Median length of stay in intensive care unit during first } 120 \mathrm{hr} \text { (IQR) } \\
\qquad-\mathrm{hr}\end{array}$ & $\begin{array}{c}68.0 \\
(49.3 \text { to } 93.6)\end{array}$ & $\begin{array}{c}69.8 \\
(50.3 \text { to } 94.3)\end{array}$ & 0.24 \\
\hline $\begin{array}{l}\text { No. of episodes of in-hospital worsening of heart failure during first } \\
120 \mathrm{hr}\end{array}$ & 115 & 126 & 0.63 \\
\hline In-hospital worsening of heart failure during first $120 \mathrm{hr}-$ no. (\%) & $90(8.3)$ & $94(8.8)$ & 0.70 \\
\hline $\begin{array}{l}\text { Rehospitalization for heart failure } \leq 30 \text { days after index hospital } \\
\text { discharge }- \text { no./total no. (\%) }\end{array}$ & $75 / 1055(7.1)$ & $74 / 1053(7.0)$ & 1.00 \\
\hline $\begin{array}{l}\text { Median duration of intravenous therapy for heart failure during } \\
\text { index admission (IQR) - hr }\end{array}$ & $\begin{array}{c}70.5 \\
(42.7 \text { to } 115.4)\end{array}$ & $\begin{array}{c}68.9 \\
(44.6 \text { to } 115.5)\end{array}$ & 0.53 \\
\hline 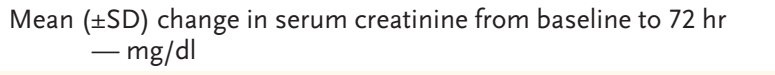 & $0.15 \pm 0.38$ & $0.09 \pm 0.33$ & 0.002 \\
\hline $\begin{array}{l}\text { All-cause mortality or hospitalization for a cardiovascular cause } \\
\text { at } 6 \text { mo - no. (\%) }\end{array}$ & $443(40.7)$ & $398(37.2)$ & 0.10 \\
\hline \multicolumn{4}{|l|}{ Biomarkers of drug response } \\
\hline \multicolumn{4}{|l|}{ Decrease in N-terminal proBNP from baseline to $48 \mathrm{hr}$} \\
\hline No. of patients evaluated & 967 & 956 & \\
\hline Median (IQR) - pg/ml & $\begin{array}{c}-3816 \\
(-7166 \text { to }-1614)\end{array}$ & $\begin{array}{c}-2595 \\
(-5611 \text { to }-574)\end{array}$ & $<0.001$ \\
\hline \multicolumn{4}{|l|}{ Ratio of cardiac troponin $\mathrm{T}$ at $48 \mathrm{hr}$ vs. baseline } \\
\hline No. of patients evaluated & 603 & 579 & \\
\hline Median (IQR) & 1.01 (0.86 to 1.19$)$ & $1.00(0.88$ to 1.15$)$ & 0.70 \\
\hline
\end{tabular}

* The analyses of secondary outcome measures are exploratory, because the protocol specified the performance of hierarchical testing of the secondary outcomes only if the result for at least one of the coprimary outcomes was significant.

Because the tests for the two coprimary outcomes were not significant, and given the hierarchical testing plan, all secondary end-point analyses were exploratory. There was no benefit of ularitide for any of the clinical secondary outcome measures (Table 2).

\section{BIOMARKERS OF DRUG RESPONSE}

The mean decrease in systolic blood pressure in the ularitide group was greater by $6.8 \mathrm{~mm} \mathrm{Hg}$ at 6 hours and by $3.9 \mathrm{~mm} \mathrm{Hg}$ at 48 hours than in the placebo group ( $\mathrm{P}<0.001$ for both comparisons); these between-group differences dissipated over a period of 72 to 120 hours (Fig. S4 in the Supplementary Appendix). Among the 1923 patients
(89\%) for whom data were available, the magnitude of the decrease in levels of NT-proBNP at 48 hours was $47 \%$ greater in the ularitide group than in the placebo group $(\mathrm{P}<0.001)$. Cardiac troponin $\mathrm{T}$ measurements were obtained at baseline and at 48 hours in 1182 patients (55\%); there was no significant between-group difference in the change in the cardiac troponin $\mathrm{T}$ level between baseline and 48 hours $(\mathrm{P}=0.70)$ (Table 2).

During the first 48 hours, there were 55 adjudicated episodes of in-hospital heart-failure events in 46 patients in the ularitide group, as compared with 87 episodes in 75 patients in the placebo group. A post hoc comparison showed that this difference was nominally significant $(P=0.005)$ 

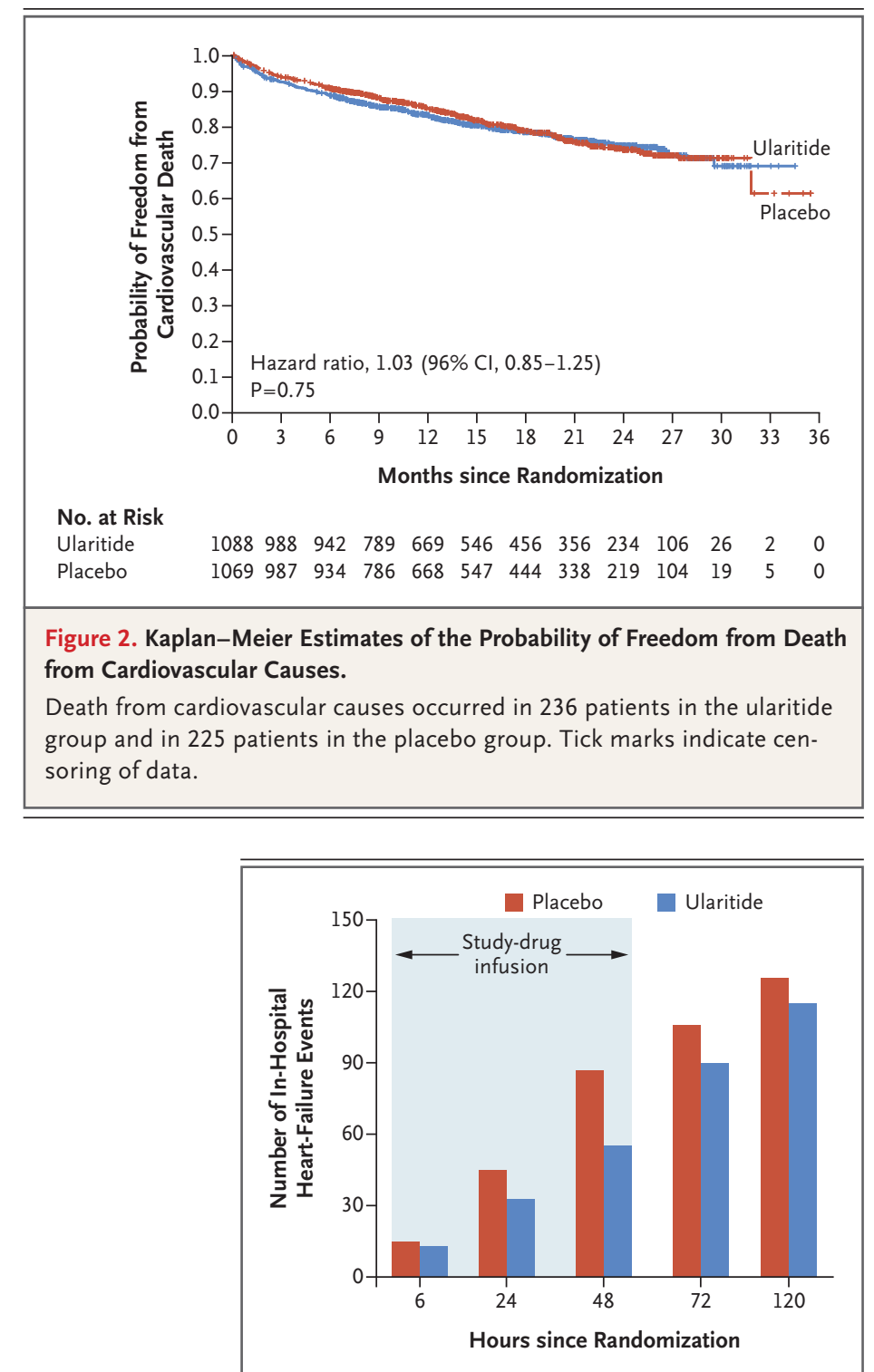

Figure 3. In-Hospital Heart-Failure Events.

Investigators recorded each episode of persistent or worsening heart failure as an event requiring a specific intervention during the interval from the initiation of the study-drug infusion to 120 hours. A patient could have more than 1 heart-failure event during the study interval. (Details regarding the definition of persistent or worsening heart failure are provided in the Supplementary Appendix.) The cumulative total number of in-hospital heart-failure events during the 120-hour period was 115 in the ularitide group and 126 in the placebo group, a difference that was not significant $(P=0.63)$. However, in a post hoc analysis, the cumulative total number of in-hospital heart-failure events during the first 48 hours (i.e., during the study-drug infusion) was 55 in the ularitide group and 75 in the placebo group, a difference that was nominally significant $(P=0.005)$.
(Fig. 3). (The timing and treatment of these events are summarized in Tables S5 and S6 in the Supplementary Appendix.) The between-group difference in in-hospital heart-failure events dissipated after the cessation of study-drug treatment.

\section{SAFETY}

Patients in the ularitide group were more likely than those in the placebo group to have hypotension and to discontinue treatment because of it (Table S7 in the Supplementary Appendix). At 48 hours, the ularitide group had significantly higher hematocrit values $(\mathrm{P}<0.001)$ and serum creatinine levels $(\mathrm{P}=0.005)$ and lower hepatic aminotransferase values $(\mathrm{P}<0.001)$ than did those in the placebo group (Table $S 8$ in the Supplementary Appendix). The increase in the serum creatinine level persisted at 72 hours but not after 30 days.

\section{SCUSSION}

In the TRUE-AHF trial, ularitide exerted its expected short-term hemodynamic effects. ${ }^{21}$ The drug produced systemic vasodilation (as evidenced by decreases in systolic blood pressure), which was accompanied by decreases in NT-proBNP levels (reflecting a reduction in cardiac-wall stress). Both the hematocrit and serum creatinine levels increased during the infusion, pointing to hemoconcentration ${ }^{22-24}$ and (together with a decrease in liver enzymes indicative of less hepatic congestion ${ }^{9}$ ) to aggressive decongestion; these effects were paralleled by a decrease in the rate of in-hospital heart-failure events during the infusion. Such early worsening events have been linked to increases in both cardiac filling pressures and cardiac troponin levels, ${ }^{25-28}$ which suggests that these events may reflect undertreated ventricular distention and acute cardiac injury at the time of initial admission. A reduction in cardiac-wall stress that is achieved rapidly after clinical presentation might be expected to reduce myocardial necrosis, preserve ventricular function, maintain clinical stability, and reduce the long-term risk of cardiovascular death. ${ }^{9-12}$

However, even though the time from clinical evaluation to pharmacologic intervention was shorter than in previous studies, ${ }^{14-16,29-32}$ and despite evidence of meaningful cardiac decongestion, the long-term risk of cardiovascular death was not reduced among patients who received ularitide. This lack of benefit raises doubt about 
the theories that early ventricular distention causes myocardial necrosis and adversely affects the natural history of heart failure after hospitalization and that rapid reversal of short-term ventricular distention preserves myocardial viability. ${ }^{911,12,16,17,31}$ For all the patients who underwent randomization, a clinical composite end point was also not affected by treatment.

Our findings differ from those of the RELAXAHF trial, in which treatment with the vasodilator serelaxin (at a median of 7 hours after clinical evaluation) led to decreases in NT-proBNP levels and in rates of in-hospital worsening of heart failure, reductions that were followed by decreases in cardiovascular mortality. ${ }^{9,14}$ However, in the RELAX-AHF trial, the reported survival benefits may have been due to chance, since investigators did not adjudicate in-hospital heartfailure events, the trial was not designed to reliably evaluate the risk of cardiovascular death, and the reduced risk of death was least apparent among patients who received very early therapy. ${ }^{33}$ The patients who received serelaxin had a small $(<10 \%)$ transient decrease in cardiac troponin levels, a finding that was not observed in TRUEAHF or in trials of other vasodilators. ${ }^{27,34}$ The importance of this finding is questionable, since serelaxin did not reduce mortality in the recently completed RELAX-AHF-2 trial. ${ }^{35}$

Hypotension was an expected side effect of ularitide. In other large-scale trials involving patients with acute heart failure, hypotension that was reported before the initiation of the infusion or during the infusion was associated with unfavorable effects on morbidity and mortality, ${ }^{15,36}$ which suggests that hypotension may limit the benefits of any reduction in cardiac-wall stress. However, our patients had higher systolic blood pressures than did the patients with acute heart failure who were enrolled in most earlier trials, ${ }^{15,29-32}$ so they should have had better tolerance for vasodilator therapy. In the RELAX-AHF trial, serelaxin was associated with hypotensive effects similar to those reported in our trial. ${ }^{37}$

The results of our trial should be interpreted with caution. Our study design allowed patients to receive the study drug very early after the initial clinical evaluation (median, 6 hours). Possibly, even earlier intervention (e.g., 1 to 3 hours after evaluation) might have shown more favorable results, although the subgroup of patients with the earliest intervention did not have a more favorable response in our trial or in an earlier study. ${ }^{34}$ Cardiac troponin $\mathrm{T}$ was remeasured at only one point in time and in only about half the patients; our findings might have been different if we had sampled this value more extensively. However, cardiovascular mortality was not reduced by ularitide, so any drug-related effect on myocardial injury that we might have missed was transient and unlikely to have been clinically relevant.

In conclusion, we evaluated the effect of early administration of the vasodilator ularitide in patients with acute heart failure. Ularitide reduced cardiac-wall stress more markedly than placebo, as indicated by more rapid reduction in NT-proBNP levels. However, in an intention-to-treat analysis, the drug did not reduce myocardial injury (as indicated by cardiac troponin $\mathrm{T}$ levels), did not affect a clinical composite end point, and did not influence disease progression, as shown by the lack of effect on cardiovascular mortality.

\footnotetext{
Supported by Cardiorentis.

Disclosure forms provided by the authors are available with the full text of this article at NEJM.org.
}

\section{APPENDIX}

The authors' full names and academic degrees are as follows: Milton Packer, M.D., Christopher O'Connor, M.D., John J.V. McMurray, M.D., Janet Wittes, Ph.D., William T. Abraham, M.D., Stefan D. Anker, M.D., Ph.D., Kenneth Dickstein, M.D., Gerasimos Filippatos, M.D., Richard Holcomb, Ph.D., Henry Krum, M.D., Ph.D., Aldo P. Maggioni, M.D., Alexandre Mebazaa, M.D., Ph.D., W. Frank Peacock, M.D., Mark C. Petrie, M.D., Piotr Ponikowski, M.D., Ph.D., Frank Ruschitzka, M.D., Dirk J. van Veldhuisen, M.D., Lisa S. Kowarski, B.A., Mark Schactman, M.H.S., and Johannes Holzmeister, M.D.

The authors' affiliations are as follows: the Baylor Heart and Vascular Institute, Baylor University Medical Center, Dallas (M.P.), and Baylor College of Medicine, Houston (F.P.) - both in Texas; Inova Heart and Vascular Institute, Falls Church, VA (C.O.); the Institute of Cardiovascular and Medical Sciences, BHF Glasgow Cardiovascular Research Centre, University of Glasgow, Glasgow, United Kingdom (J.J.V.M., M.C.P.); Statistics Collaborative, Washington, DC (J.W., L.S.K., M.S.); Ohio State University Heart and Vascular Center, Columbus (W.T.A.); Innovative Clinical Trials, Department of Cardiology and Pneumology, University Medical Center Göttingen, Göttingen, Germany (S.A.); the Division of Cardiology, University of Bergen, Stavanger University Hospital, Stavanger, Norway (K.D.); Faculty of Medicine, National and Kapodistrian University of Athens, Athens (G.F.); private consultant, Wayzata, MN (R.H.); Centre of Cardiovascular Research and Education in Therapeutics, Monash University, Melbourne, VIC, Australia (H.K.); Centro Studi, Associazione Nazionale Medici Cardiologi Ospedalieri, Fondazione Per il Tuo Cuore HCF ONLUS, Florence, Italy (A.P.M.); University Paris 7 Diderot, Assistance Publique-Hôpitaux de Paris, Department of Anesthesia and Critical Care, Hôpitaux Universitaires Saint-Louis Lariboisière, U 942 INSERM, Paris (A.M.); Wroclaw Medical University, Wroclaw, Poland (P.P.); the Department of Cardiology, University Hospital Zurich, Zurich (F.R., J.H.), and Cardiorentis, Zug (J.H.) - both in Switzerland; and the University Medical Center Groningen, Groningen, the Netherlands (D.J.V.). 
REFERENCES

1. Blecker S, Paul M, Taksler G, Ogedegbe G, Katz S. Heart failure-associated hospitalizations in the United States. J Am Coll Cardiol 2013;61:1259-67.

2. Peacock WF IV, De Marco T, Fonarow $\mathrm{GC}$, et al. Cardiac troponin and outcome in acute heart failure. $\mathrm{N}$ Engl J Med 2008; 358:2117-26.

3. Felker GM, Mentz RJ, Teerlink JR, et al. Serial high sensitivity cardiac troponin $\mathrm{T}$ measurement in acute heart failure: insights from the RELAX-AHF study. Eur J Heart Fail 2015;17:1262-70.

4. Drexler B, Heinisch C, Balmelli C, et al. Quantifying cardiac hemodynamic stress and cardiomyocyte damage in ischemic and nonischemic acute heart failure. Circ Heart Fail 2012;5:17-24.

5. Solomon SD, Dobson J, Pocock S, et al. Influence of nonfatal hospitalization for heart failure on subsequent mortality in patients with chronic heart failure. Circulation 2007;116:1482-7.

6. Fonarow GC, Peacock WF, Horwich $\mathrm{TB}$, et al. Usefulness of B-type natriuretic peptide and cardiac troponin levels to predict in-hospital mortality from ADHERE. Am J Cardiol 2008;101:231-7.

7. Scirica BM, Sabatine MS, Jarolim P, et al. Assessment of multiple cardiac biomarkers in non-ST-segment elevation acute coronary syndromes: observations from the MERLIN-TIMI 36 trial. Eur Heart J 2011;32:697-705.

8. Heestermans $T$, van 't Hof AW, ten Berg JM, et al. The golden hour of prehospital reperfusion with triple antiplatelet therapy: a sub-analysis from the Ongoing Tirofiban in Myocardial Evaluation 2 (On-TIME 2) trial early initiation of triple antiplatelet therapy. Am Heart J 2010;160: 1079-84.

9. Metra M, Cotter G, Davison BA, et al. Effect of serelaxin on cardiac, renal, and hepatic biomarkers in the Relaxin in Acute Heart Failure (RELAX-AHF) development program: correlation with outcomes. J Am Coll Cardiol 2013;61:196-206.

10. Maisel AS, Peacock WF, McMullin N, et al. Timing of immunoreactive B-type natriuretic peptide levels and treatment delay in acute decompensated heart failure: an ADHERE (Acute Decompensated Heart Failure National Registry) analysis. J Am Coll Cardiol 2008;52:534-40.

11. Peacock WF, Emerman C, Costanzo MR, Diercks DB, Lopatin M, Fonarow GC. Early vasoactive drugs improve heart failure outcomes. Congest Heart Fail 2009;15: 256-64.

12. Wong YW, Mentz RJ, Felker GM, et al. Nesiritide in patients hospitalized for acute heart failure: does timing matter? Implication for future acute heart failure trials. Eur J Heart Fail 2016;18:684-92.

13. Ponikowski P, Voors AA, Anker SD, et al. 2016 ESC guidelines for the diagnosis and treatment of acute and chronic heart failure: the task force for the diagnosis and treatment of acute and chronic heart failure of the European Society of Cardiology (ESC) developed with the special contribution of the Heart Failure Association (HFA) of the ESC. Eur Heart J 2016;37: 2129-200.

14. Teerlink JR, Cotter G, Davison BA, et al. Serelaxin, recombinant human relaxin-2, for treatment of acute heart failure (RELAX AHF): a randomised, placebo-controlled trial. Lancet 2013;381:29-39.

15. Packer M, Colucci W, Fisher L, et al. Effect of levosimendan on the short-term clinical course of patients with acutely decompensated heart failure. JACC Heart Fail 2013;1:103-11.

16. Cuffe MS, Califf RM, Adams KF Jr, et al. Short-term intravenous milrinone for acute exacerbation of chronic heart failure: a randomized controlled trial. JAMA 2002;287:1541-7.

17. Packer M, Holcomb R, Abraham WT, et al. Rationale for and design of the TRUE-AHF trial: the effects of ularitide on the short-term clinical course and long-term mortality of patients with acute heart failure. Eur J Heart Fail 2016 November 13 (Epub ahead of print).

18. Mitrovic V, Lüss $\mathrm{H}$, Nitsche $\mathrm{K}$, et al Effects of the renal natriuretic peptide urodilatin (ularitide) in patients with decompensated chronic heart failure: a doubleblind, placebo-controlled, ascending-dose trial. Am Heart J 2005;150:1239.

19. Mitrovic V, Seferovic PM, Simeunovic D et al. Haemodynamic and clinical effects of ularitide in decompensated heart failure. Eur Heart J 2006;27:2823-32.

20. Packer M. Development and evolution of a hierarchical clinical composite endpoint for the evaluation of drugs and devices for acute and chronic heart failure: a 20-year perspective. Circulation 2016;134: 1664-78.

21. Anker SD, Ponikowski P, Mitrovic V, Peacock WF, Filippatos G. Ularitide for the treatment of acute decompensated heart failure: from preclinical to clinical studies. Eur Heart J 2015;36:715-23.

22. van der Meer P, Postmus D, Ponikowski $\mathrm{P}$, et al. The predictive value of shortterm changes in hemoglobin concentration in patients presenting with acute decompensated heart failure. J Am Coll Cardiol 2013;61:1973-81.

23. Testani JM, Chen J, McCauley BD Kimmel SE, Shannon RP. Potential effects of aggressive decongestion during the treatment of decompensated heart failure on renal function and survival. Circulation 2010;122:265-72.

24. Davila C, Reyentovich A, Katz SD. Clinical correlates of hemoconcentration during hospitalization for acute decompensated heart failure. J Card Fail 2011; 17:1018-22

25. Cotter G, Metra M, Weatherley BD, et al.
Physician-determined worsening heart failure: a novel definition for early worsening heart failure in patients hospitalized for acute heart failure - association with signs and symptoms, hospitalization duration, and 60-day outcomes. Cardiology 2010;115:29-36.

26. Butler J, Gheorghiade M, Kelkar A, et al. In-hospital worsening heart failure. Eur J Heart Fail 2015;17:1104-13.

27. Felker GM, Hasselblad V, Tang WH, et al. Troponin I in acute decompensated heart failure: insights from the ASCEND-HF study. Eur J Heart Fail 2012;14:1257-64. 28. DeVore AD, Greiner MA, Sharma PP, et al. Development and validation of a risk model for in-hospital worsening heart failure from the Acute Decompensated Heart Failure National Registry (ADHERE). Am Heart J 2016;178:198-205.

29. O'Connor CM, Starling RC, Hernandez $\mathrm{AF}$, et al. Effect of nesiritide in patients with acute decompensated heart failure. N Engl J Med 2011;365:32-43.

30. McMurray JJ, Teerlink JR, Cotter G, et al. Effects of tezosentan on symptoms and clinical outcomes in patients with acute heart failure: the VERITAS randomized controlled trials. JAMA 2007;298: 2009-19.

31. Massie BM, O'Connor CM, Metra M, et al. Rolofylline, an adenosine $\mathrm{A}_{1}$-receptor antagonist, in acute heart failure. N Engl J Med 2010;363:1419-28.

32. Gheorghiade M, Konstam MA, Burnett JC Jr, et al. Short-term clinical effects of tolvaptan, an oral vasopressin antagonist, in patients hospitalized for heart failure: the EVEREST Clinical Status Trials. JAMA 2007;297:1332-43.

33. Metra M, Ponikowski P, Cotter G, et al. Effects of serelaxin in subgroups of patients with acute heart failure: results from RELAX-AHF. Eur Heart J 2013;34:312836.

34. Breidthardt T, Noveanu M, Potocki M, et al. Impact of a high-dose nitrate strategy on cardiac stress in acute heart failure: a pilot study. J Intern Med 2010;267: 322-30.

35. Novartis heart drug portfolio hit by failed serelaxin study. Reuters, March 22, 2017 (http://www.reuters.com/article/ us-novartis-heart-idUSKBN16T0QG).

36. Patel PA, Heizer G, O'Connor CM, et al. Hypotension during hospitalization for acute heart failure is independently associated with 30-day mortality: findings from ASCEND-HF. Circ Heart Fail 2014;7:91825.

37. FDA briefing document: Cardiovascular and Renal Drugs Advisory Committee meeting, March 27, 2014 (http://www .fda.gov/downloads/AdvisoryCommittees/ CommitteesMeetingMaterials/Drugs/ CardiovascularandRenalDrugsAdvisory Committee/UCM390443.pdf).

Copyright (c) 2017 Massachusetts Medical Society. 